\title{
Gender and children's wellbeing: four Mediterranean countries in perspective
}

\begin{abstract}
In this paper, we discuss gender disparities in children's wellbeing using the Integrated Fuzzy and Relative (IFR) methodology adapted to the framework of the Capability Approach. The aim is to obtain insights into the multidimensional nature of children's wellbeing by considering seven children's capabilities. The study is conducted using cross-sectional data from the 2009 European Survey on Income and Living Conditions (EU-SILC) referring to four Southern European countries: Portugal, Italy, Greece and Spain. The role of gender in children's wellbeing is investigated by using two different perspectives at the household level: the gender of single parents and the gender of the children. The results indicate that there is a gender effect from both the investigated perspectives. Thus, our findings suggest that dimension-specific and gendered policies are needed to improve children's wellbeing.
\end{abstract}

Keywords: Children's wellbeing, multidimensional and fuzzy set approach, Capability Approach, gender disparities

\section{Introduction}

Even if gender inequality derives from a biological category, one's sex, that is, in general, not changeable and thus rewards and punishes people for an ascriptive characteristic they are born with (Klasen, 2004: 3), gender inequality is actually recognized as a critical issue in modern societies in Europe and other economies around the world because it reflects the idea and situation that women and men are not equal. Sen $(2009$, p. 166) refers to the social tendency to see gender disparity as a "normal phenomenon". It is also true that gender inequality is an issue that should be taken into consideration in a wide range of socio-economic fields and measures, but we only concentrate our attention on gender disparities in children's wellbeing. Our analysis is based on household-level 
data, since the household can be an important site of gendered practices. Indeed, either measuring differences by gender of single-parent households or by comparing households with only female or male children using a multidimensional perspective adds new knowledge in the wide framework of children's wellbeing.

Wellbeing incorporates the concept of a "good life" of individuals, whether they are adults or children. The question of the conditions and the meaning of the "good life" have been on the agenda of social theory, social policy and research since Aristotle. Wellbeing reflects the quality of life of a person and illustrates the state of doing well. Measuring wellbeing is complicated and multifaceted, as an individual's current and future state of wellbeing depends upon a myriad of variables, each of which can differ greatly, depending upon the population sub-group and the geographical and cultural characteristics of the location being studied. Nevertheless, as Bastos and Machado (2009) asserted in their paper, focusing only on an economic approach fails to capture other dimensions that influence wellbeing and thereby child poverty; moreover, Bastos et al. (2004) stressed that income poverty and child deprivation do not overlap, although they are associated.

Walker and Unterhalter (2007) assert that the Capability Approach (CA) offers a broad normative framework to conceptualize and evaluate individual wellbeing and social arrangements in any context or society. Iversen (2003) further stresses that the CA facilitates interpersonal comparisons of opportunities for achieving wellbeing, whereas Klasen (2004) argues that examining wellbeing in the space of capabilities, as advocated by Sen (e.g., 1999), might be particularly suitable to capture the gender dimension of wellbeing. The $\mathrm{CA}$ is a normative framework that sheds light on what beings are capable of being and doing. The term capability represents the alternative combinations of things that a person is able to do or be - the various "functionings" that he or she can achieve (Sen, 1993). To contribute to these debates, this paper uses the CA approach to study gender disparities in children's wellbeing. In particular, it applies a methodology based on the multidimensional fuzzy approach (Lemmi et al., 2010), adapted to the framework of the CA by 
Potsi et al. (2016), in a cross-country perspective.

The novelty of this study is that it goes beyond the impact of economic restrictions - which has been broadly discussed in the literature - on children's capabilities and investigates the role that gender might play. Therefore, the monetary dimension is only marginally used in our analysis, as our main interest is non-monetary dimensions that contribute to children's wellbeing and their interplay with gender.

The cross-country perspective completes our analysis. We have chosen four countries - namely, Italy, Portugal, Greece and Spain - that are categorized as Mediterranean or Southern European social welfare regime states owing to their socio-economic similarities (Püss et al., 2010; Kornrich and Eger, 2016). Püss et al. (2010) describe this social model as a family-focused one in which the state addresses only specific social risks against which families cannot protect themselves. The main traits of this regime are strict unemployment insurance legislation, high poverty risk and relatively low unemployment benefits, employment rates and expenditures on social protection. Accordingly, countries' performances are compared in terms of the extent to which children's wellbeing differs systematically by gender. The cross-sectional data constraint limits the analysis presented in this article to the year 2009; however, in this year, the 2008 financial crisis was already underway, and thus, such an investigation could offer a better understanding of children's wellbeing in time of crisis in countries in which the welfare regime particularly exposes children to the risk of deprivation.

The structure of the article is as follows. In section 2, we briefly discuss the background and introduced theoretical insights regarding gender inequality in childhood and parenthood. In section 3, we present the methodology used. The data and empirical strategy are presented in section 4 . The results are discussed in section 5. The paper ends with a brief list of conclusions and future developments in section 6 . 


\section{Background}

\subsection{Conceptualization of Children's wellbeing using the capability approach}

As asserted by Raghavan and Alexandrova (2015), there has not been much discussion regarding what constitutes children's wellbeing. Currently, there are many interpretations of this subject, depending on the aspect being considered and conceptual approach employed. The study of children's wellbeing is characterized by a plurality of approaches and measures because it is a very complex concept, with a multifaceted nature, and it is also crucial to policy making (Ben-Arieh et al., 2014). In particular, the measurement and the development of indicators of children's wellbeing have expanded in recent years (Ben-Arieh and Goerge, 2001; Ben-Arieh, 2010; Lippman, 2007), with the aim of tracking the wellbeing of children at a social, national, or international level (BenArieh and Goerge 2006). The aim of this paper is to measure and monitor children's wellbeing using the CA and to bring attention to gender disparities. Although we do not aim to fully discuss the definition of children's wellbeing, it is worth noting that we embrace the idea that children's wellbeing should be understood in terms of the children's experience and from their perspective. Thus, we should know, for instance, how many children are able to enjoy recreational activities and whether their playgrounds are safe. In other words, we claim the use of direct measures, focusing on children and their status and putting children in the context of their environment. This information not only provides a measure of children's wellbeing but also reveals how well or poorly a society is addressing its responsibility to their children. Since the concept of wellbeing includes 'happiness' in addition to the standard of living, it is also important to stress that we develop our investigation of children's life quality with the use of objective indicators (or material elements) that indicate whether children suffer from important deprivations (e.g. poor housing conditions, poor quality of the social and natural environment, or lack of safety and security). These indicators enable us to assess whether children grow up in circumstances that allow them to develop their full potential and could also be regarded as indicators of well-becoming rather than of wellbeing. Thus, the current 
analysis does not consider measures of children's subjective wellbeing, which concerns how children and young people assess their lives, in particular, how satisfied or happy they are with aspects of their lives or their lives overall (Axford et al., 2014).

We use the CA as a conceptual framework and as a normative tool to analyse the wellbeing of children and child poverty. Namely, what matters for children's wellbeing are their functionings and capabilities. Therefore, through the CA, we are interested in determining what children are effectively able to do and to be (capabilities are children's potential functionings, and functionings are 'achievements' and 'outcomes'). The systems of indicators that we use were created exclusively by adults. Indeed, there is an implicit agreement conferring the main responsibility for the wellbeing of children to parents (Gaitan Munoz, 2010). Parents of all interests are and remain the lawful representatives of their children (Wiesner et al., 1995, cited in Sünker \& Swiderek, 2005). Consequently, the welfare situation of children depends mainly on the cultural, social, and economic position, i.e. class-based milieus (cf. Vester et al., 2001; Bourdieu, 1984), of their parents, with the implication that children will be as wealthy or as poor as their parents are. As members of the same family unit, parents and children obviously share many situations, although not from the same vantage point, owing to generational differences in childhood environment and life stage. To organize our research and classify children's conceptualization of capabilities, we chose the categories presented in Potsi et al. (2016), as we will explain in section 4.

\subsection{Children's welfare in Mediterranean countries}

European countries are characterized by different welfare models. Esping-Andersen (1990) identified three models: the Nordic socio-democratic model, the Continental corporatist model and the Anglo-Saxon liberal model. Later, a fourth model, the Mediterranean model, was introduced (Ferrera, 1996). Greece, Italy, Spain and Portugal are usually considered to employ this model (Aiginger and Leoni, 2009; Puss et al. 2010; Diamond and Lodge, 2013). 
A major distinction among these welfare models concerns the share of public expenditure devoted to social transfers and the subdivision among the different functions ${ }^{1}$. A specific function refers to the needs of families and children. As stated by the European Social Protection Committee (2008), social transfers represent a relevant proportion of the gross income of households with children living below the poverty line, with family allowances playing the biggest role in supplementing the income of these households. Additionally, other descriptive and empirical studies have found that family policy regimes matter for children's wellbeing (see Aguayo et al. (2016) and Engster and Stensota (2011). Thus, investigating the share of the total social transfers that are devoted to the family/children function in a country can give us a hint about the support that households, and specifically households with children, receive from a country's welfare systems.

Considering Eurostat data ${ }^{2}$ from 2009, we can see that the share of the total benefits devoted to the family/children function was equal to the $4 \%$ in Greece, $4.8 \%$ in Italy, $5.5 \%$ in Portugal and $6.2 \%$ in Spain. In the same year, this share was equal to $8.1 \%$ in France, $11.2 \%$ in the UK, and $12.7 \%$ in Norway, with an average value for the 28 countries of the European Union equal to $8.6 \%$. Considering the social protection for family/children expenses per inhabitant (in purchasing power standards, hereafter PPS), Greece, Italy, Portugal and Spain spend much less than the EU average of 600.8 PPS, with values ranging from 223.9 to 352 PPS. These data confirm that countries that employ the Mediterranean welfare model devote a reduced share of their social spending to households and children compared to other European countries. For this reason, we argue that households' and children's wellbeing can be more threatened in these countries, where some specific social risks are left behind in favour of others (e.g. old-age and unemployment benefits). Thus, specific empirical analyses investigating children's wellbeing in Southern European countries are particularly worth and urgent, especially with a focus on gender disparities.

\footnotetext{
${ }^{1}$ We refer to the social protection benefits classification in the European system of integrated social protection statistics (ESSPROS). Social protection benefits are defined as transfers to households, in cash or in kind, intended to relieve them of the financial burden of several risks and needs. These include disability, sickness/healthcare, old age, survivors, family/children, unemployment, housing and social exclusion not covered elsewhere.

${ }^{2}$ The data can be obtained from http://ec.europa.eu/eurostat/web/social-protection/data/main-tables
} 


\subsection{Gender inequality in the family structure}

Gender refers to the socially constructed roles, behaviours, activities and attributes that a society at a given time and place considers appropriate for men and women - or boys and girls - and the relationships between them. Therefore, West and Zimmermann (1987) argued that gender is not something we are but rather something we do. Gender is continually socially reconstructed within the spectrum of normativity.

Gender is conceived as a product of culture and upbringing. Societies structure and nurture ideals about men's and women's “proper” roles in family life, society and paid work. According to Durkin (2005:159), "gender is given, grown, imposed, expected, regulated, learned, reflected upon, enacted, experienced, and shared. In this complex, multifaceted, and multidetermined minefield, children are actively engaged as thinkers and as emotional beings striving to relate who they are and how they relate to the social structure". We must admit that in modern western societies, ideals have shifted toward more egalitarian views. Nevertheless, there is a discrepancy between ideals and realities. Gender inequality is often rooted at all levels of society and thus requires changing both institutional structures and individual behaviours. The main structures in which gender inequalities are reproduced or ameliorated are the state, family and labour market (González et al., 1999). Sen (1985) represents the household not as an undifferentiated unit but rather as a unit of cooperation, in addition to inequality and internal discrimination. Nevertheless, gender inequality in the home is often less measurable and visible than inequalities in formal markets; e.g. labour markets generated in the home and therefore outside of formal markets are typically more prone to inequality (Klasen, 2004).

Despite the widening of family forms, the traditional family model is still privileged and/or prevailing, especially within Southern countries. Gonzales et al. (1999) argue that Southern European countries share common traits in terms of the manner in which gender roles and responsibilities are embedded in social policies and law. According to Gonzales et al. (2013, p. 
167), customary patterns of conduct are simply taken as legitimate and even reasonable, and in most parts of the world, there is a shared tendency not to notice the systematic deprivation of females visa-vis males in one field or another.

Gender differences analysed in a multidimensional perspective, as the CA is (Sen, 1985), allow us to detect different aspects of wellbeing that can enable children, especially girls, to become agents in their own lives. We consider the family as the statistical unit of observation; therefore, the children's condition in terms of wellbeing is indirectly evaluated through the family (see, for example, Chen et al., 2005). Using this approach, the required assumption is that household-level conditions affect all individuals living in the household, including children (Eurostat, 2012) ${ }^{3}$. Gender-specific social and behavioural norms are embedded within the family structure and context. Data from historical and cross-cultural analyses highlight differences across time and place in proscribed roles for girls and boys in their families and corresponding differences between the social roles of women and men (McHale et al., 2003).

In this framework, this paper aims to analyse children's wellbeing from a gender perspective at the family level. Previous studies have investigated the role that gender plays on children's subjective (Kaye-Tzadok et al., 2017) or objective (Modroño et al., 2013) wellbeing and on parents' wellbeing (Roeters and Gracia, 2016) by using data at the individual level. Specifically, in this paper, it is decided to group families in two manners: first, we investigate the intersection of single-parents' gender in relation to children's wellbeing; second, we investigate children's gender in a traditional family model in relation to children's wellbeing. Those two family structures' comparisons provide fruitful insights into the conjunction of gender and children's wellbeing.

Previous studies have emphasised that the gender of single parents can impact children's behaviours, such as children's time use (Mencarini et al., 2014). Moreover, gender statistics

\footnotetext{
${ }^{3}$ Obviously, the manners in which and degree to which these conditions affect household members could be different, but this issue cannot be resolved with these data. However, the EU-SILC 2009 data also provide answers to specific questions related to children that partially correct this problem.
} 
(OECD, 2010) reveal that the proportion of sole mothers in paid employment is usually greater than that of partnered mothers in most countries, particularly in Greece, Italy and Spain. In these countries, sole mothers must engage in paid work because public benefits for sole parents are low, and thus sole mothers often rely on informal networks for childcare support. Children's care is a matter of the family, and the care of the family is most often the responsibility of women (see Lewis and Giullari, 2005). Given misperceptions, it may be a difficult task to overcome gender inequalities and indeed even to identify them clearly as inequalities that demand attention. Since gender inequalities within the family tend to survive by making allies out of the deprived, the opaqueness of the positional perspectives plays a major part in the prevalence and persistence of these inequalities (Gonzales et al., 2013; p. 169). Demuth and Brown (2004) note that children's health outcomes vary between single-mother and single-father families, and it is therefore advisable to distinguish between the two. Rollero et al. (2014) report several findings supporting the evidence for gender differences in terms of vulnerability to some determinants of health and wellbeing. Thus, the gender of single parents may impact not only children's financial opportunities but also children's living environment and non-monetary deprivation. Our aim is to obtain some insights into the influence of single parents' gender on specific children's capabilities, going beyond the single monetary dimension and therefore offering a more interesting and complete picture of the effect of gender on children's wellbeing.

Concerning children's gender, studies have suggested that this may be a key component to understand the importance of family structure and family processes for children's wellbeing (for a reference, see Vandewater and Lansford, 1998). For example, the gender of children has implications for the manners in which parents treat, spend time with, invest in, and ultimately receive care from their children later in life (Raley and Bianchi, 2006). By analysing US data, Marks et al. (2009) found that girl-girl and boy-boy sibling dyads have a different impact on family patterns and conflicts. Focusing also on an economical perspective, Dahl and Moretti (2008) found that parents favouring boys over girls is not confined to the past and that because of the effects of 
gender on family structure, first-born girls and their siblings often live in families in which the income is lower, the poverty rate is higher, welfare participation is higher, home ownership is lower, and child support payments following divorce are lower. Nilsson (2016) recently examined gender differences in several dimensions of family-related variables in the explanation of adolescent offending in Sweden, and his findings suggest that the mechanisms of social bonding seem to operate in somewhat different manners for boys and girls. Researchers from a social learning perspective have found evidence for parents' differential treatment of girls versus boys (McHale et al. 2003: 127). Addabbo et al. (2014) assert that in Italy, girls' and boys' capabilities differ in terms of both their measurement and causes. Volkert and Schneider (2012) offer an interesting overview of children's wellbeing from a CA perspective and discuss various empirical analysis based also on a gender perspective. In the present study, we investigate whether children's gender plays a role in determining their level of wellbeing as measured using a multidimensional approach based on the CA.

Indeed, as already emphasised, in this work, we move beyond the sole monetary dimension of deprivation using a multidimensional approach based on the $\mathrm{CA}$, and to some extent, we follow feminist studies that have consistently stressed the importance of a more holistic conceptual and empirical approach to encapsulate gender deprivation. Nevertheless, a crucial concern in the study of children's wellbeing from the CA perspective is the choice of obtaining the data with either nonparticipatory or participatory methods. The analysis performed relies on the former method, i.e. we employ secondary data to analyse children's wellbeing according to their functionings and capabilities. Therefore, the dimensions included in our analysis and the method proposed for studying gender-related issues are constrained by the information contained in the European Survey on Income and Living Conditions (EU-SILC), which in turn provides a high level of comparability across countries. 


\section{Methodology: the Integrated Fuzzy Relative approach}

The Integrated Fuzzy and Relative (IFR) approach is a multivariate statistical methodology proposed by Cheli and Lemmi (1995) and then updated by Betti et al. (2006) and Lemmi et al. (2010) for studying multidimensional poverty by using a fuzzy set approach. The main features of this approach are the following: i) the assumption that poverty is a vague predicate that manifests itself in different shades and degrees (fuzzy concept) rather than an attribute that is simply present or absent for individuals in the population, as the traditional poverty approach assumes; ii) a multidimensional perspective of poverty that provides a better understanding of people wellbeing since quality of life is something more than simply a given amount of resources. Dang (2014) also stressed that the fuzzy set theory is a technique used to operationalize the CA and that it is particularly suitable in the CA framework. Accordingly, Potsi et al. (2016) adapted the IFR approach in the framework of CA for studying children's capabilities deprivation in Italy, and Potsi et al. (2017) applied the proposed methodology in a comparative perspective across countries. From a methodological point of view, the IFR approach in the framework of CA is strictly related to the statistical methodology known as latent variable models (Bartholomew and Knott, 1999). The main idea of this methodology is that the theoretical concept is not directly observable; rather, it is latent (hidden), and the observed indicators (outcomes or responses) are partial/imperfect measures of this underlying theoretical concept. In the CA framework, most of the empirical analyses are based on this latent variable approach, in which the capability set or the degree of choice of an individual is assumed to be unobservable (latent), with each observed outcome (functioning) representing a partial manifestation of it.

Econometric models known as Multiple Indicator Multiple Causes models (Jöreskog and Goldberger, 1975), hereafter MIMIC, are suitable examples of latent variable approaches in the CA framework, and indeed, they have been used by several researchers, including Di Tommaso (2007), Krishnakumar (2007), Krishnakumar and Ballon (2008), and Addabbo and Di Tommaso (2009). The IFR methodology is an alternative methodology that is related to the latent variable approach 
owing to its basic assumption that poverty is a multidimensional concept that is not directly observable, namely, it is comprised by different latent dimensions, and specific groups of several observed indicators are partial measures of each latent dimension.

In particular, the IFR approach is applied to a set of different non-monetary indicators, assumed to be the manifest representation of a restricted number of underlying dimensions of wellbeing, in addition to a monetary indicator based on the household equivalent disposable income. The implementation of the IFR methodology involves several steps. Below, we briefly describe the main outputs; for more details regarding the overall approach and the relevant formulas, we refer to Betti et al. (2015), Betti and Verma (2008), and Berti et al. (2014). Starting from the set of observed indicators, a membership function with values on the $[0,1]$ interval is defined for each dimension to which indicators belong (factor analysis is typically used to group indicators into dimensions). This function is some quantitative specification of individual/household degrees of poverty and wellbeing/deprivation, depending on the other individuals or households included in the analysis. Accordingly, a membership function's value of 0 is always associated with the lowest risk of poverty and deprivation (i.e., the highest level of wellbeing), whereas a value of 1 is associated with the highest risk (i.e., the lowest level of wellbeing). Membership function values between 0 and 1 indicate intermediate degrees of wellbeing/deprivation. Since a membership function is defined for each wellbeing dimension under study, for the sake of simplicity, let $s(s=1, \ldots, S)$ be the $s$-th dimension of wellbeing in the set of $S$ wellbeing dimensions, where $S$ - 1 are the non-monetary dimensions and the last is the monetary dimension. We indicate by $Y_{F n M(s)}(s=1, . ., S-1)$ the membership function of each non-monetary dimension and by $Y_{F M}$ and $Y_{F n M}$ the membership function of the monetary and the overall non-monetary dimensions, respectively (see Potsi et al. 2016 for formal procedures for obtaining $Y_{F M}, Y_{F n M}$ and each $\left.Y_{F n M(s)}\right)$. These functions are calculated separately for each country $i(i=1, \ldots, I)$. Therefore, let $j\left(j=1, \ldots, n_{i}\right)$ be the $j$-th individual in country $i$; if $Y_{i j, F n M(s)}=1$ and $Y_{i j, F M}=1$, the $j$-th individual is deprived in terms of all 
dimensions considered, whereas if $Y_{i j, F n M(s)}=0$ and $Y_{i j, F M}=0$, the $j$-th individual is not deprived in terms of any dimensions. Accordingly, as values increase from 0 to 1 , the wellbeing of the $j$-th individual in terms of the relevant dimension decreases. In each dimension and country, several combinations of values can be observed: we compute the average values of $\bar{Y}_{F n M(s)}, s=1, \ldots, S-1$, $\bar{Y}_{F M}$ and $\bar{Y}_{F n M}$ to measure the degree of wellbeing observed at the country level in terms of the corresponding dimension. It is worth noting that due to methodological constraints, both $\bar{Y}_{F M}$ and $\bar{Y}_{F n M}$ at the country level are equal to the At Risk of Poverty Rate (ARPR), even if the meaning of these indicators is completely different. The two fuzzy indicators measure the degree of deprivation, whereas the ARPR is the traditional poverty measure, that is, the share of people with disposable income less than the poverty threshold, which is set at the $60 \%$ of the national median equivalised disposable income (again, see Potsi et al. 2016 for further details).

\section{Data and Operationalisation}

\subsection{Data}

Our empirical analysis is based on the cross-sectional EU-SILC 2009 data. The EU-SILC is an annual survey performed simultaneously by all EU member states with the aim of collecting timely and comparable cross-sectional and longitudinal multidimensional micro data regarding income, poverty, social exclusion and living conditions. In 2009, the questionnaire of the survey was expanded by adding a module about material deprivation, including questions specific to children, to the standard core survey (European Commission, 2009). For this reason, even if defining children's capabilities using EU-SILC data is non-trivial, we believe that the use of this source of data is an important opportunity. EU-SILC data are available and comparable for 32 European countries, thus allowing cross-countries comparisons of households and children living conditions also from a multidimensional perspective (see, for example, de Neubourg et al., 2012). Moreover, the availability of both monetary and non-monetary items of households' wellbeing enables the inclusion of both of these aspects in the multidimensional analysis. Finally, the use of EU-SILC data 
also enables longitudinal analysis regarding the improvement or worsening of children's wellbeing.

Our analysis focuses on children aged 0-14 years and in four countries, Italy, Portugal, Greece and Spain. Although significant works in the field consider children as those aged 0 to 17 years, the age range of $0-14$ years was chosen in this study. This decision was made owing not only to data constraints (e.g. some of the items used in our analysis are child-specific and collected only for children under 16) but also the conviction that these age groups may well be subject to higher vulnerability and intergenerational dependence. Moreover, the age of 14 corresponds to a decisive transition point in children's lives in most Southern European countries because until that age, children in Italy attend the same compulsory schools - elementary plus secondary lower school/basic education - whereas in the following years, they can differentiate their educational path, e.g. choosing between schools more tailored to university studies or to the labour market. The same also occurs in Greece and Portugal, whereas in Spain, compulsory education terminates at the age of 16 .

Table 1 reports, for each country, the sample size of households with children and the number of individuals living in these households, together with the respective population percentages.

Table 1 - Country sample size - households with children

\begin{tabular}{ccccc}
\hline Country & \# households & \% of total households & \# individuals & \% of total individuals \\
\hline Portugal & 1197 & 29 & 4749 & 41 \\
Italy & 5030 & 23 & 19128 & 37 \\
Greece & 1664 & 25 & 6599 & 36 \\
Spain & 3662 & 26 & 14535 & 39 \\
\hline
\end{tabular}

Note: the effective sample size used for computing fuzzy measures is the one resulting after deleting observations with missing values in several items (118 and 3 households in Greece and Spain respectively, for a total number of individuals equal to 698)

In accordance with the map of birth rate across Europe (OECD, 2010), the incidence of households with children varies among the four countries; the lowest share is in Italy, and the highest in Portugal. 


\subsection{Operationalisation}

Applying the IFR methodology in the CA framework involves a series of steps that we briefly describe. As explained above, the latent dimensions corresponding to the capability set or the degree of choice of an individual are assumed to be represented by partial manifestations of them. These observed indicators have been selected from the list of target secondary variables relating to material deprivation available in the EU-SILC data special module 2009.

Generally, the choice of these observed outcomes is a crucial issue in any CA analysis, and it is often constrained by the available data and theoretical framework. Nevertheless, the EU-SILC data offer a wide choice of single items to be selected as potential functionings in our approach. The final choice of the items was also based on a literature review regarding children's capabilities (Nussbaum, 2006; Wüst and Volkert, 2012; Modroño et al., 2013). Even though these studies differ depending on the context, the area of analysis and the age group, they paved the way for the selection of the items analysed in this paper. The theoretical model is summarized in Figure 1 by using the typical graphical representation used in the latent variable approach. In Figure 1, the selected indicators are classified into seven domains that each represent a latent dimension (capability). In particular, these dimensions are the following: i) PLAY, ii) AFFILIATION \& SOCIAL LIFE, iii) NUTRITION \& CLOTHING, iv) FINANCIAL ISSUES, v) SHELTER, vi) SAFETY, and vii) BODILY HEALTH. In addition, material wellbeing related to family and child's material resources, such as income, has also been considered. The target variable for the monetary dimension is the equivalised household disposable income.

We argue that play is vital for children's social development and is a crucial aspect of the human life for healthy growth and wellbeing. The manifest representation of PLAY are the following observed indicators: outdoor leisure equipment, indoor games and books at home suitable for the child's age. Moreover, material wellbeing, measured as material deprivation concerning NUTRITION \& CLOTHING, is another crucial aspect to be considered because of its impact on children's potential. The ability to be "well" nourished and to be "well" clothed with new clothes 
and shoes are the observed indicators considered for measuring this dimension. The third capability concerns material wellbeing linked to FINANCIAL ISSUES, related to the wealth of the households in which children live. This capability, reflecting the ability of the household to address unexpected costs, is measured using five observed indicators: the (in)ability to cope with unexpected expenses, arrears on bills, hire purchase instalments and mortgage payments and the (in)ability to keep the house warm. AFFILIATION \& SOCIAL LIFE concerns other children's activities, such as hobbies and children's relations with other people, such as friends and peers from school and/or the neighbourhood. The ability of the child to live with others and to engage in various forms of social interaction are the manifest representations of this capability. SHELTER represents the housing context related to housing physical conditions that may well intersect with children's health. SAFETY is indeed linked to neighbourhood environment. It considers the prevalence or absence of crime, violence, pollution and noise in children's environment. Finally, BODILY HEALTH refers to lack of resources for children's general health, and it is represented by two components focusing on access to medical attention from specialists. For further discussion of these domains, see Potsi et al. (2016).

To assess the construct's internal consistency of the assumed factor structure (Figure 1), Cronbach's alpha indicator was used (Nunnally and Bernstein, 1994), and the overall assessment of the theoretical framework was evaluated by Confirmatory Factor Analysis (CFA) in the empirical analysis, as required by the IFR methodology. We present the main results of these analyses in section 5. Therefore, operationally children's capabilities represent the set composed by the $S-1$ dimensions. In each of the four countries, we then measure the degree of wellbeing/deprivation in the corresponding capability computing $\bar{Y}_{F n M(s)}$ ( $s=$ PLAY, NUTRITION \& CLOTHING, FINANCIAL ISSUES, AFFILIATION \& SOCIAL LIFE, SAFETY, BODILY HEALTH and SHELTER), in addition to the average value for the monetary dimension $\bar{Y}_{F M}$ and the overall nonmonetary indicator $\bar{Y}_{F n M}$, which summarises in a single indicator the $S$-1 non-monetary dimensions. 


\section{Figure 1 - Indicators affecting Capabilities: Path Diagram*}

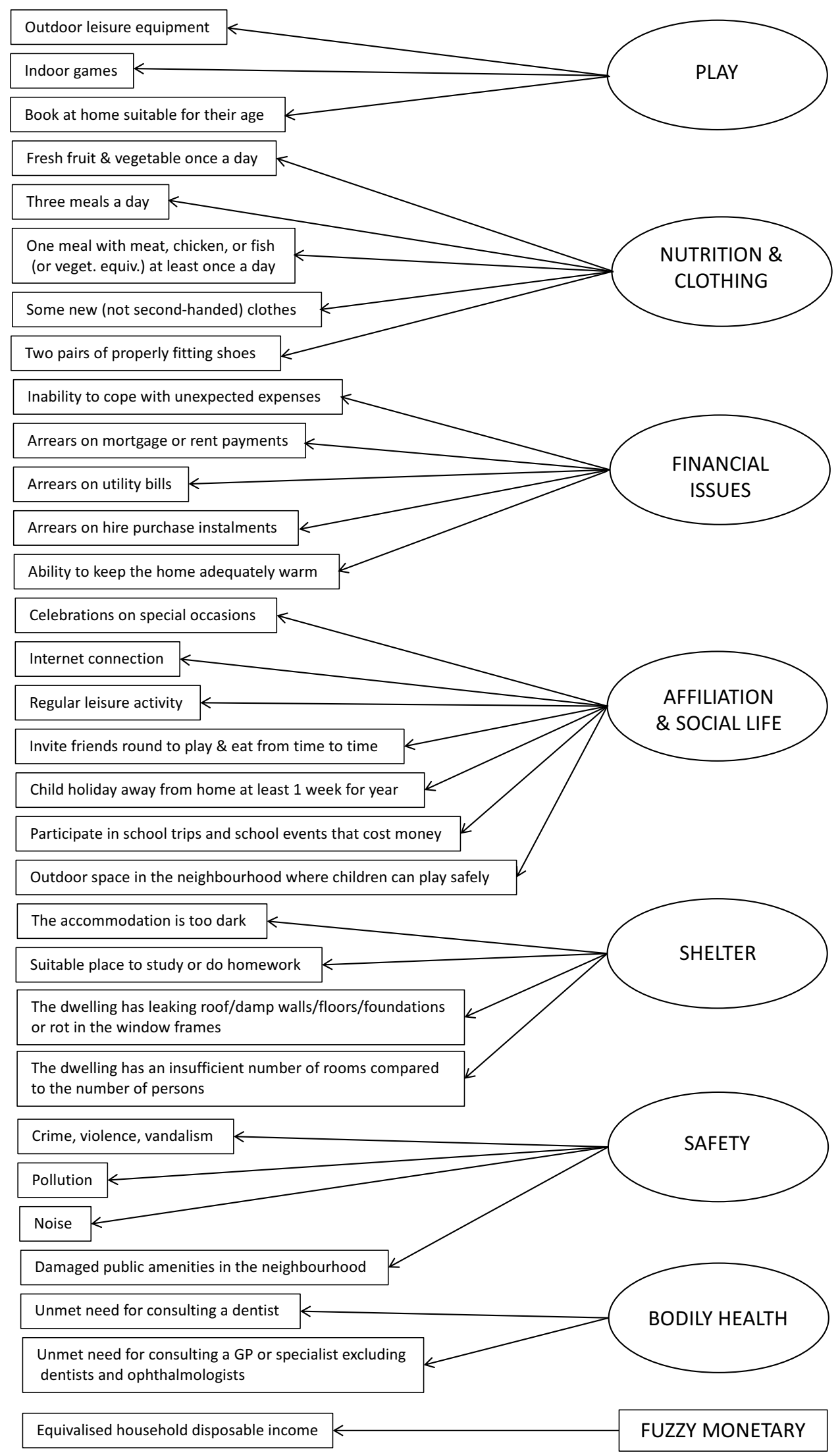

*Note: we make use of a simplified version (i.e. without symbols and formulas) of a path diagram usually used in the latent variable approach. The ovals represent latent variables (factors). Each factor points to more than one observed variable (functioning, represented by a rectangle). 


\section{Descriptive statistics and assessment of the theoretical framework}

In Table 2, the population of households with children is decomposed in terms of the characteristics accounting for gender differences. We concentrate our attention on two specific factors: the gender of single parents and the gender of the children. These two socio-demographic characteristics of households with children are also informative about the different social environment prevailing in each country.

Table 2 - Household characteristics by country (percentages).

\begin{tabular}{llcccc}
\hline \multicolumn{1}{c}{ Household characteristics } & & Portugal & Italy & Greece & Spain \\
\hline \multirow{2}{*}{ Single parent* } & Male & 1.4 & 2.5 & 1.2 & 1.8 \\
& Female & 5.8 & 4.4 & 3.2 & 4.1 \\
\hline \multirow{2}{*}{ Children* } & Only males & 38.2 & 36.5 & 32.6 & 35.8 \\
& Only females & 39.0 & 39.1 & 35.9 & 37.8 \\
\hline
\end{tabular}

*Note: percentages of the other family structures are not reported since they can be easily obtained (for example for Portugal 100-1.4-5.8 $=92.8$ is the percentage of the remaining family structures with respect to the covariate single parent).

In general, regardless the gender aspect, single parents with children account for a low percentage of households across the four countries, with a very similar share. As expected, in each country, the fraction of female single parents is approximately double that of male single parents.

The last rows of Table 2 report the children's gender. To consider children's gender, in the below analyses, we always compare households with one or two children to deduct the effect of the household sample size. The findings reveal similar distributions of children's gender in Italy, Portugal, Greece and Spain.

In Table 3, the sample size of individuals living in households with male or female single parents and in households with one/two male or female children is reported.

In Table 4, the results of the reliability analysis are reported. The cut-off value for Cronbach's alpha, which denotes good internal consistency of the scale, is 0.60 or higher; thus, the seven latent factor scales identified reveal a good global internal consistency in almost all the countries. Even though the SHELTER and SAFETY dimensions exhibit lower values of Cronbach's alpha in 3 out of four 
countries, the overall assessment of this theoretical framework is confirmed by the Confirmatory Factor Analysis (CFA) discussed in the next section.

Table 3 - Number of individuals living in households with specific characteristics, by country.

\begin{tabular}{llcccc}
\hline Household characteristics & & Portugal & Italy & Greece & Spain \\
\hline \multirow{2}{*}{ Single parent } & Male & 91 & 408 & 69 & 310 \\
& Female & 317 & 937 & 300 & 812 \\
\hline \multirow{3}{*}{ Children } & One male & 1418 & 4944 & 1263 & 3944 \\
& One female & 1380 & 4945 & 1363 & 3361 \\
& Two males & 446 & 1955 & 690 & 1458 \\
& Two females & 327 & 1797 & 627 & 1302 \\
\hline
\end{tabular}

Note: Results comparing households with three children or more are not presented because of the small sample size.

Table 4 Reliability analysis: Cronbach's alpha by country

\begin{tabular}{lcccc}
\hline Domain & PT & IT & EL & ES \\
\hline PLAY & 0.75 & 0.78 & 0.72 & 0.69 \\
NUTRITION \& CLOTHING & 0.74 & 0.75 & 0.45 & 0.80 \\
FINANCIAL ISSUES & 0.62 & 0.65 & 0.65 & 0.68 \\
AFFILIATION \& SOCIAL LIFE & 0.75 & 0.75 & 0.70 & 0.69 \\
SHELTER & 0.56 & 0.62 & 0.58 & 0.39 \\
SAFETY & 0.56 & 0.64 & 0.58 & 0.55 \\
BODILY HEALTH & 0.68 & 0.66 & 0.76 & $*$ \\
\hline
\end{tabular}

* This dimension is not considered for Spain because of lack of available information.

Moreover, several scholars recommend being cautious when formulating general guidelines regarding alpha. Schmitt (1996) perceives the use of any cut-off value as short-sighted because satisfactory levels of alpha depend on test use and interpretation. In addition, he notes that alpha increases as a function of test length: "When a measure has other desirable properties, such as meaningful content coverage of some domain and reasonable unidimensionality, this low reliability may be not a major impediment to its use" (Schmitt, 1996). Accordingly, we conclude that the reliability analysis provides acceptable results for each country. 
We used Confirmatory Factor Analysis (CFA) to determine whether the hypothesized seven-factor structure, shown in Figure 1, provides a good fit to the data in each country. In other words, we tested whether relationships between the observed indicators (functionings) and their underlying latent constructs (capabilities) exist. The CFA outcomes provide information about each indicator's significance. When running CFA, many different fit statistics can be used to help determine whether the model provides an adequate fit to the data. Whereas there are no golden rules for assessment of model fit, reporting a variety of indices is necessary because different indices reflect different aspects of model fit. Among the others, Hoyle and Panter (1995) present guidelines for reporting information regarding CFA model fitting. To assess the fit of the latent structural model, the chisquare value was not computed since it is highly dependent on the sample size. Instead, the Adjusted Goodness of Fit Index (AGFI), the Root Square Mean Error of Approximation (RMSEA) and the Normed Fixed Index (NFI) were calculated. The AGFI was 0.87 or greater for the four countries, where achieving a value close to 1 indicates a good fit. The RMSEA expresses the unexplained or residual variance of the factor structure; it ranged from 0.05 for Italy to a maximum of 0.06 for the other three countries. Values of this statistic between 0.05 and 0.08 indicate reasonable errors of approximation in the population. The NNFI, which was equal to 0.80 or greater in three out of four countries, met the criteria for an acceptable fit ( 0.80 or greater). For Spain, even though the value of NNFI is less than 0.80 , the remaining two indicators indicate a reasonable fit; therefore, we conclude that the conceptual framework is sufficiently supported in all of the four countries.

Table 5 - Robustness analysis of the hypothesized structure: CFA by country

\begin{tabular}{lcccc}
\hline Index & PT & IT & EL & ES \\
\hline Adjusted for Degrees of Freedom (AGFI) & 0.87 & 0.91 & 0.90 & 0.90 \\
Root Square Mean Error of Approximations (RMSEA) & 0.06 & 0.05 & 0.06 & 0.06 \\
Bentler \& Bonett's (1980) Non-Normed Fixed Index NNFI & 0.80 & 0.86 & 0.80 & 0.70 \\
\hline Number of dimensions & 7 & 7 & 7 & $6^{*}$
\end{tabular}

*The BODILY \& HEALTH dimension is not considered for Spain because of lack of available information. 


\section{Findings}

\subsection{Measuring wellbeing in households with children}

At the country level, the monetary indicator $\left(\bar{Y}_{F M}\right)$ is a measure of the monetary degree of wellbeing. It is slightly higher in Greece and Spain than in the other two countries (see the first column in Table 6); thus, the level of monetary wellbeing based on household income in Greece and Spain is less than that observed in Italy and Portugal. As expected, when households with children are taken into account, we first notice a decrease in the degree of wellbeing in all of the countries (second column of Table 6). This result confirms that children are among the most deprived groups in the population, together with people aged over 65 years old and young people (Busetta and Milito, 2010; Tarki 2010).

Comparing the monetary wellbeing of households with children among the four countries, we observe a lower value for Portugal, followed by Italy and then Greece and Spain. Comparing the values of the $\bar{Y}_{F M}$ indicator in the overall population with the ones referring to households with children, Italy exhibits the greatest difference, followed by Spain. Namely, children are more exposed to the risk of deprivation in Italy and Spain than in the other two countries. Indeed, at least for Italy, this type of family combines also another determinant factor of the phenomenon: large families are more likely to live in the south of the country. Potsi et al. (2016) further investigated this aspect by differentiating the analysis in terms of Italian geographical macro-areas. The present findings that confirm this empirical evidence and add new information through a cross-country comparison. Child deprivation, in addition to being serious in itself, tends to result in intergenerational transmission of poverty (the link between being born poor and remaining poor for the rest of one's life; see Jenkins and Siedler, 2007), and the highest gap observed for Italy exacerbates this problem. Generally, in most societies, minors are regarded as vulnerable people who need more protection. The evidence that the gap is greater in Italy than in the other three countries that have similar welfare systems should be considered and deeply investigated by policy 
makers. Indeed, this phenomenon may lead to social conflicts between those who enjoy wellbeing and those who have scarce resources.

Table 6 - Well-being indicators at country level.

\begin{tabular}{|c|c|c|c|c|c|c|c|c|c|}
\hline \multirow[b]{3}{*}{ COUNTRY } & \multirow{3}{*}{$\begin{array}{c}\begin{array}{c}\text { All } \\
\text { households* }\end{array} \\
\bar{Y}_{F M}\end{array}$} & \multicolumn{8}{|c|}{ Households with children } \\
\hline & & \multirow[b]{2}{*}{$\bar{Y}_{F M}$} & \multicolumn{7}{|c|}{ Ratio to OVERALL non-monetary indicator (i.e. $\left.\bar{Y}_{F n M}(s) / \bar{Y}_{F n M}\right)$} \\
\hline & & & PLAY & $\begin{array}{c}\text { NUTRITION } \\
\& \\
\text { CLOTHING }\end{array}$ & $\begin{array}{l}\text { FINANCIAL } \\
\text { ISSUES }\end{array}$ & $\begin{array}{l}\text { AFFILIATION } \\
\& \text { SOCIAL LIFE }\end{array}$ & SHELTER & SAFETY & $\begin{array}{l}\text { BODILY } \\
\text { HEALTH }\end{array}$ \\
\hline Portugal & 0.182 & 0.205 & 0.593 & 0.510 & 0.733 & 0.833 & 0.774 & 0.814 & 0.318 \\
\hline Italy & 0.184 & 0.235 & 0.291 & 0.290 & 0.683 & 0.727 & 0.723 & 0.829 & 0.156 \\
\hline Greece & 0.201 & 0.242 & 0.362 & 0.209 & 0.787 & 0.725 & 0.702 & 0.811 & 0.116 \\
\hline Spain & 0.201 & 0.247 & 0.220 & 0.189 & 0.672 & 0.733 & 0.665 & 0.764 & - \\
\hline
\end{tabular}

*Note: the population overall deprivation indicator is equal to its corresponding monetary deprivation indicator, the ARPR, as explained in section 3.2. Therefore, the higher values of the at risk of poverty rate for all the households are observed for Greece and Spain, where the percentage of households with an equivalized income below the country specific poverty line is equal to $20,1 \%$. The values observed for Portugal and Italy are slightly lower $(18,2 \%$ and $18,4 \%$ respectively).

A more complete evaluation of children's wellbeing can be drawn from the right part of Table 6 (columns three through nine). The estimated fuzzy measures corresponding to the capabilities set complete our information about children's wellbeing, considering other non-monetary dimensions of wellbeing. Rather than showing the actual values $\overline{\mathrm{Y}}_{\mathrm{FnM}}(\mathrm{s})$, for each country, we present the ratios $\overline{\mathrm{Y}}_{\mathrm{FnM}}(\mathrm{s}) / \overline{\mathrm{Y}}_{\mathrm{FnM}}$. Thus, a higher ratio indicates a higher importance of the corresponding children's capability in determining the overall country wellbeing. It is worth noting that at the country level, $\overline{\mathrm{Y}}_{\mathrm{FnM}}$ and $\overline{\mathrm{Y}}_{\mathrm{FM}}$ are equal for methodological constrains, as explained in section 3. Therefore, the ratios $\bar{Y}_{\mathrm{FnM}}(\mathrm{s}) / \overline{\mathrm{Y}}_{\mathrm{FnM}}$ are equivalent to the ratios $\overline{\mathrm{Y}}_{\mathrm{FnM}}(\mathrm{s}) / \overline{\mathrm{Y}}_{\mathrm{FM}}$. Nevertheless, this equality does not matter, and it is not particularly interesting from an empirical point of view, whereas the multidimensional investigation of these ratios adds further evidence to our analysis. In general, from Table 6, we observe low values for the dimensions PLAY, NUTRITION \& CLOTHING, and BODILY HEALTH. From a wellbeing perspective, these low values suggest that wellbeing in terms of these dimensions is greater than that in terms of the other dimensions. Namely, in all 
countries, the capability to play, to be adequately nourished and dressed, and to be able to have good health have a relatively small importance compared with the overall non-monetary indicator.

More specifically, the dimension BODILY HEALTH exhibits the lowest importance in all of the countries for which data are available, whereas for Spain, the lowest value is the one associated with the PLAY dimension. Moreover, the second-lowest value is always observed for the dimensions PLAY or NUTRITION \& CLOTHING. It is interesting to note that in a qualitative study, Brown (2012) showed that for children living in abject poverty, despite their material deprivation, play is rich in terms of many of the most fundamental aspects of a healthy play experience. The author argued, based on his study alone, that it would be reasonable to conclude that the link between poverty and play deprivation is tenuous at best.

At the opposite side, children's wellbeing is in terms of the dimensions FINANCIAL ISSUES, AFFILIATION \& SOCIAL LIFE, SHELTHER and SAFETY. We observe higher ratios for all of the countries considered, indicating that the deprivation in terms of these capabilities is elevated, and therefore their effect on the overall indicator is strong. Considering the individual countries, we note that for Italy, Portugal and Spain, the two highest ratios are those referring to the SAFETY and AFFILIATION \& SOCIAL LIFE dimensions. As Potsi et al. (2016) demonstrated for the case of Italy, these results reveal a "duality" of life discrepancy between the internal sphere of the family and the external sphere. Deprivation in terms of aspects such as health and play are more amenable to alternative non-monetary resourcing, whereas this is not always possible for aspects of social life and safety. For Greece, the two highest ratios indicate the highest deprivation in terms of the dimensions SAFETY and FINANCIAL ISSUES, followed in third place by AFFILIATION \& SOCIAL LIFE. Thus, we can say that for this country, whereas SAFETY is still a significant concern, as in the other countries, the inability to address unexpected expenses is a more relevant issue. 
To summarise, the results that we obtained for children's wellbeing, as measured in terms of the CA approach across the four countries and seven dimensions, suggest that further reflection regarding the total benefits devoted to the family/children function in these countries is necessary. Indeed, the similar welfare of the four countries, as demonstrated in section 2, also indicates a very similar scenario concerning children's wellbeing. Even if it not possible to deduce a causal relationship, it is interesting to observe this result. Eurostat data referring to other European countries ${ }^{4}$ confirm that Italy, Spain, Portugal and Greece are among the countries for which the gap between monetary poverty and material deprivation is greater for children than for the overall population. Thus, our findings could supply decision makers with useful information to define specific social policies with the aim of reducing the spread and depth of child deprivation in terms of particular dimensions.

\subsection{Measuring gender differences}

In addition to the overall results reported in Table 6, the effect of gender-related household characteristics has been explored, being the main interest of our analysis. We first focus on singleparent households. We do not report here the general and dimension-specific results of the effect of living in households with a single parent ${ }^{5}$, since this is not the focus of the current analysis. Nevertheless, our findings add new knowledge regarding children's wellbeing relative to the solely monetary dimension, as reported in Gornicl and Jantti (2009) or Brady and Burroway (2012), who stressed the exceptionally high poverty rates across European countries in single-parent households. Indeed, living with a single parent implies a general decrease in wellbeing of children in terms of all of the dimensions. The higher effects are those observed for the dimensions PLAY and BODILY HEALTH in Greece, whereas for the same dimensions, we observe in Portugal a higher wellbeing for children living with a single parent.

\footnotetext{
${ }^{4}$ Data available at http://ec.europa.eu/eurostat/web/income-and-living-conditions/data/main-tables

${ }^{5}$ Details regarding these analyses are available upon request to the authors.
} 
Since the general findings stressed an evident lack of opportunities in all the four countries for children living in single parent households, further considerations regarding the role of single parents' gender can be added to increase our knowledge about children's wellbeing. For each country and capability, the ratio of female single parents' values to male single parents' values is reported using a radar chart (Figure 2). The reference value for these ratios is the value one: each "star" (ratio) greater than one indicates a lower wellbeing for children living in households with a female single parent compared to children living in households with a male single parent in the corresponding capability; on the opposite end, each ratio less than one indicates a lower wellbeing for children living in households with a male single parent. Each line corresponds to a country. When some lines overlap, it means that the corresponding countries have similar ratios and thus similar wellbeing patterns.

From Figure 2, we can see that the ratios referring to the monetary indicator $\left(\bar{Y}_{F M}\right.$ observed for women $/ \bar{Y}_{F M}$ observed for men) indicate a penalty for the single-female-headed households in three of the countries (values greater than one), whereas the ratio is close to one for Greece. For the overall non-monetary indicator $\bar{Y}_{F n M}$, the ratios represented in Figure 2 indicate a penalty for females in Spain and Italy (ratio values equal to 1.23 and 1.12, respectively) and a penalty for males in Portugal (ratio 0.64), whereas the ratio is again near one for Greece.

Concerning the seven non-monetary indicators $\bar{Y}_{F n M(s)}$, we also implemented the non-parametric Dunn's test, which allows non-parametric pairwise multiple comparisons of independent groups and is therefore a useful tool for validating the results presented in Figure 2. Table 7 displays the pvalues associated with the Dunn's non-parametric tests (Dinno, 2015). ${ }^{6}$.

\footnotetext{
${ }^{6}$ The use of non-parametric tests is bounded by the strong non-normality of fuzzy measures. However, on the other hand, Dunn's test sacrifices the precision of discriminating means for the discrimination of stochastic dominance (that is, the probability that a randomly drawn observation from one group will be greater than a randomly drawn observation from another). Consequentially, the p-values reported in Table 7 do not directly refer to the ratios presented in the corresponding radar charts, but they can be used to illustrate significant differences between groups. The computation of the proper standard errors of fuzzy measures requires a methodological upgrade of the IFR procedure that is still under development and that requires household-level information from the EU-SILC that may be not available for all
} 


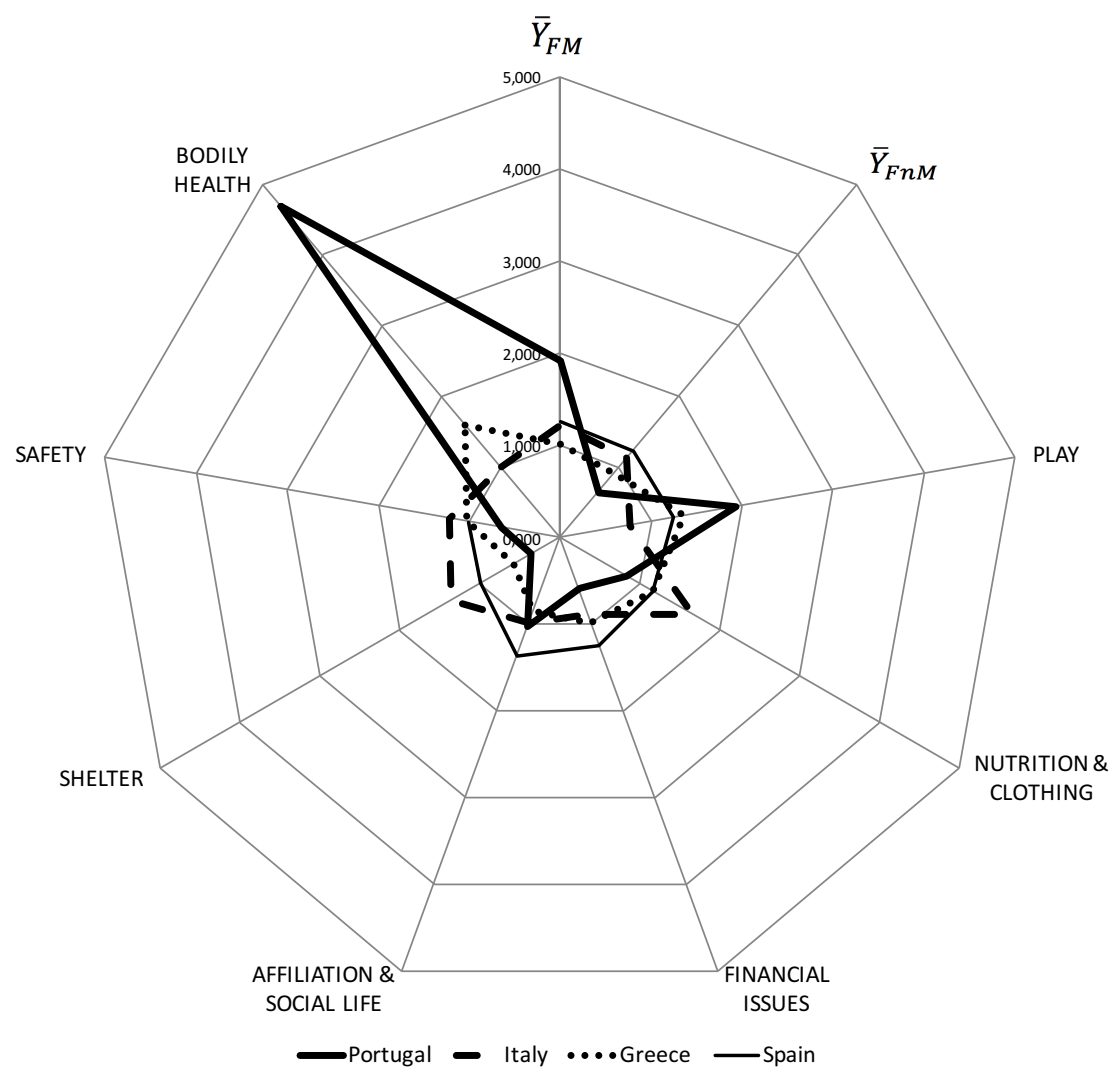

Figure 2. Female vs male single parent ratios, by well-being dimension and country.

Table 7. p-values of Dunn's tests for the comparisons between single female $v s$ single male parents, by country and well-being dimension.

\begin{tabular}{lccccccc}
\hline Country & PLAY & $\begin{array}{c}\text { NUTRITION \& } \\
\text { CLOTHING }\end{array}$ & $\begin{array}{c}\text { FINANCIAL } \\
\text { ISSUES }\end{array}$ & $\begin{array}{c}\text { AFFILIATION \& } \\
\text { SOCIAL LIFE }\end{array}$ & SHELTER & SAFETY & $\begin{array}{c}\text { BODILY } \\
\text { HEALTH }\end{array}$ \\
\cline { 2 - 8 } Portugal & 0.304 & $0.002 *$ & 0.320 & 0.214 & $0.038^{*}$ & 0.478 & $0.078^{*}$ \\
Italy & $0.043^{*}$ & $0.001 *$ & 0.211 & $0.049^{*}$ & 0.124 & 0.400 & $0.049^{*}$ \\
Greece & $0.080^{*}$ & $0.001 *$ & $0.052^{*}$ & $0.013^{*}$ & $<0.001 *$ & 0.396 & 0.203 \\
Spain & 0.263 & 0.185 & $<0.001^{*}$ & $<0.001^{*}$ & 0.411 & $0.063^{*}$ & n.a. \\
\hline
\end{tabular}

*p-values less than 0.10 indicate a significant gender effect

In general, significant gender differences are observed in each country and in each dimension, but with some exceptions. The gender effect seems to be particularly relevant for the NUTRITION \& CLOTHING capability, for which the p-values of the test are significant for three out of four countries. The corresponding ratios, represented in Figure 2, indicate a penalty for female-headed Dunn's test must be considered an easy, although crude, method of overcoming these issues. 
households in Italy (ratio of 1.65) and Greece (1.15), whereas in Portugal, the ratio is less than one (equal to 0.82), thus indicating a penalty for male-headed households. For the capability AFFILIATION \& SOCIAL LIFE, we have three significant p-values, corresponding to a ratio of greater than one for Spain (1.37), less than one for Greece (0.84) and near one for Italy. For the dimension SHELTER, the significant p-values correspond to a ratio less than one (equal to 0.3 and 0.6, respectively) for Portugal and Greece, indicating a penalty for households with male single parents. Moreover, the higher significant gender effect is the one observed for the BODILY HEALTH dimension in Portugal ( $p$-value is equal to 0.078 ), where the ratio, equal to 4.7 , indicates a large penalty for children living in households with a female single parent compared with those living in households with a male single parent. Overall, the countries in which gender effects seem more relevant are Portugal and Greece, with four significant p-values corresponding to ratios greater or less than one, followed by Italy and Spain, for which the same result is observed for two dimensions. The direction of the gender effect - if favouring children living in households with a female or male single parent - usually changes within the same dimension, with the only exception being the SHELTER dimension, for which male single parents are always associated with a lower level of wellbeing.

Therefore, our findings suggest paying attention to the gender dimension in the household structure. Since single-parent households are an increasingly common household structure in European countries (OECD, 2011), this means that many children will spend at least part of their lives in such household structures, and their wellbeing will also depend on the gender of the household head. From a welfare perspective, it would be interesting to study from a gender perspective the interplay that family/children benefits may have with parental leave and policies (Wall and Escobedo, 2013).

The gender dimension has also been explored in terms of children's gender. Despite the previous analysis, which was aimed at understanding the consequences from a gender perspective of a social dynamic that has become increasingly common in recent years, namely, single-parent households, 
this specific study is directly connected with the nature of gender, being female or male in a household. Indeed, our aim is to determine whether there is a relationship between different dimensions of children's wellbeing and children's gender considered at the household level. To perform this analysis, we only consider households in which the children are of the same gender. In doing so, we also group households by the number of children to obtain measures that are independent of the household size. Thus, in Figures 3 and 4, the radar charts report, for each capability and country, the ratio calculated by dividing the value observed for households with one female by the value observed for households with one male and that calculated by dividing the value observed for households with two females by the value observed for households with two males, respectively. We did not compare households with three or more children because the sample size was not reliable in most cases. The sample sizes for the typologies of households included in the analysis are sufficiently large, as reported in Table 3. In Figures 3 and 4, ratio values greater than one indicate a lower wellbeing for females in terms of the corresponding capability, whereas ratio values less than one indicate a penalty for males. Moreover, Table 8 , similar to Table 7, reports the p-values of non-parametric Dunn's tests comparing, for each capability, females' and males' values.

Examining the ratios represented in Figures 3 and 4 and the p-values reported in Table 8, we can observe significant differences between males and females in Portugal, Italy and partially in Greece, whereas in Spain, the effect of children's gender seems almost negligible. This result is coherent with what was found for Ireland by Watson et al. (2012), even though their approach and variables are not directly comparable with those of the present study. 


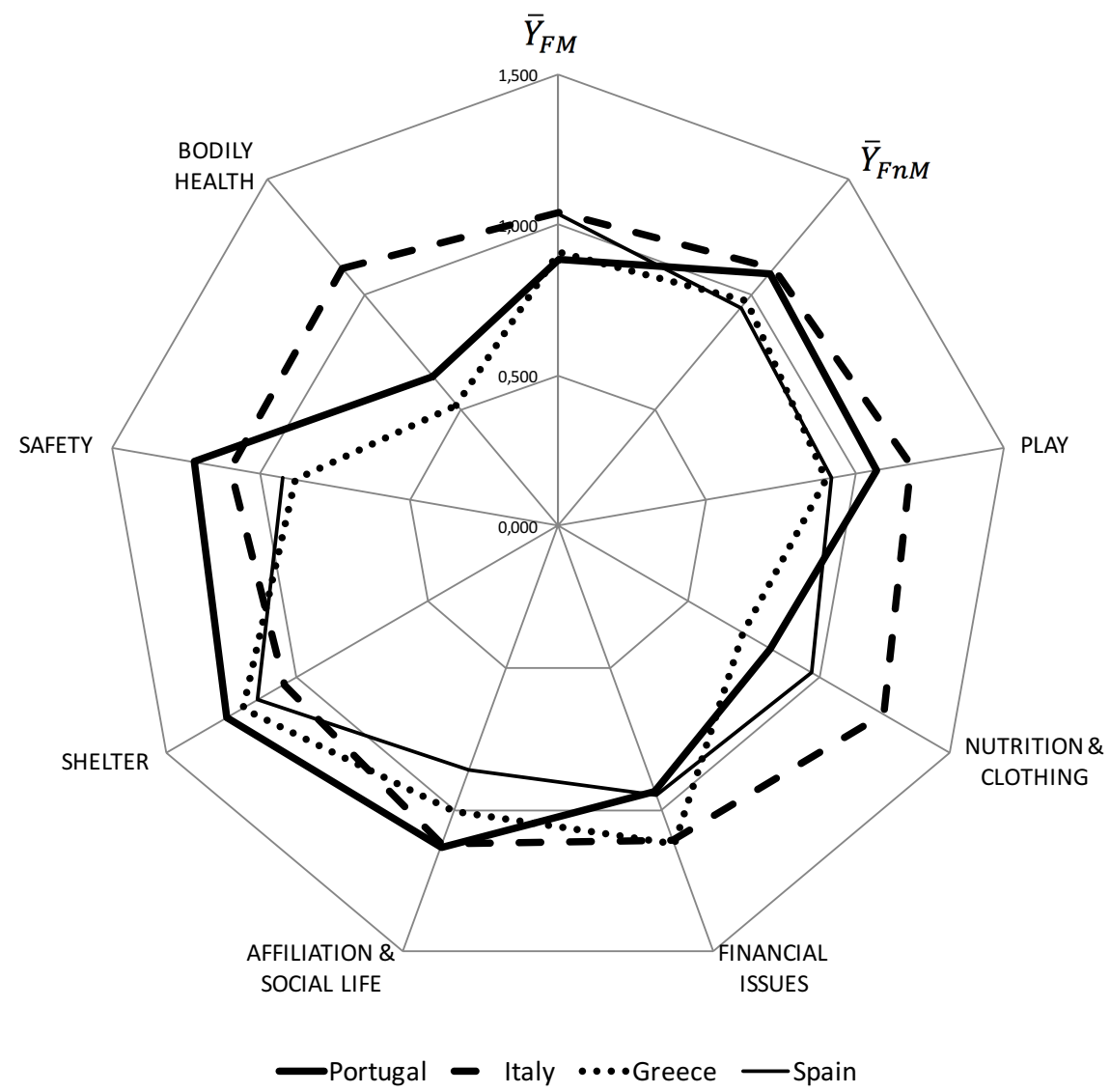

Figure 3. One female $v s$ one male child ratios, by well-being dimension and country.

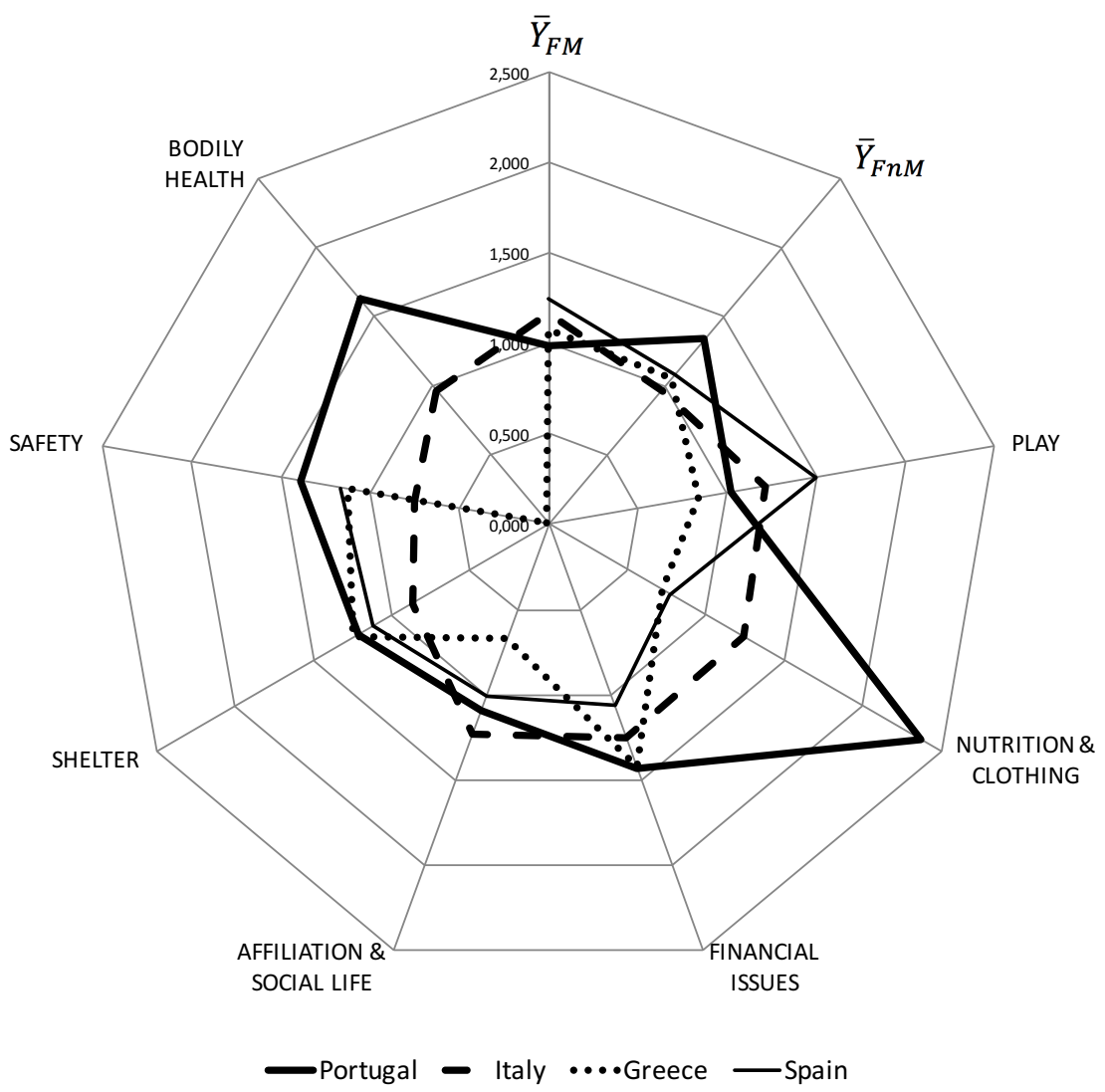

Figure 4. Two female vs two male children ratios, by well-being dimension and country. 
Table 8. $p$-values of Dunn's tests (comparisons 1 female vs 1 male and 2 females $v s 2$ males), by well-being dimension and country.

\begin{tabular}{|c|c|c|c|c|c|c|c|}
\hline Country & PLAY & $\begin{array}{c}\text { NUTRITION } \\
\& \\
\text { CLOTHING } \\
\end{array}$ & $\begin{array}{c}\text { FINANCIAL } \\
\text { ISSUES } \\
\end{array}$ & $\begin{array}{l}\text { AFFILIATION \& } \\
\text { SOCIAL LIFE }\end{array}$ & SHELTER & SAFETY & $\begin{array}{l}\text { BODILY } \\
\text { HEALTH } \\
\end{array}$ \\
\hline \multicolumn{8}{|l|}{ Portugal } \\
\hline 1 vs 1 & 0.363 & 0.631 & 0.408 & $0.067^{*}$ & $0.067^{*}$ & $0.010^{*}$ & $0.004 *$ \\
\hline 2 vs 2 & 0.474 & $0.007 *$ & $0.002 *$ & $0.043 *$ & 0.451 & 0.444 & $0.051 *$ \\
\hline \multicolumn{8}{|l|}{ Italy } \\
\hline 1 vs 1 & 0.369 & $0.044^{*}$ & $0.013 *$ & 0.427 & 0.456 & $0.058^{*}$ & 0.317 \\
\hline 2 vs 2 & 0.259 & 0.297 & $<0.001^{*}$ & $0.005^{*}$ & 0.333 & $0.037 *$ & 0.108 \\
\hline \multicolumn{8}{|l|}{ Greece } \\
\hline 1 vs 1 & 0.110 & 0.155 & 0.481 & 0.348 & 0.128 & 0.441 & $<0.001^{*}$ \\
\hline 2 vs 2 & 0.579 & 0.603 & $<0.001^{*}$ & 0.508 & 0.157 & $0.047 *$ & 0.305 \\
\hline \multicolumn{8}{|l|}{ Spain } \\
\hline 1 vs 1 & 0.234 & 0.495 & 0.265 & 0.600 & 0.309 & $0.002 *$ & n.a \\
\hline 2 vs 2 & 0.324 & 0.309 & $0.082 *$ & 0.454 & 0.344 & 0.380 & n.a \\
\hline
\end{tabular}

${ }^{*}$ p-values less than 0.10 indicate a significant effect.

Where the p-values reported in Table 8 are significant, the values of the corresponding ratios indicate in most cases a lower wellbeing for households with only female children. The only exceptions are observed for the dimension BODILY HEALTH, for which we observe ratios less than one when comparing one female versus one male in Portugal and Greece (0.65 and 0.52, respectively), and for the dimension SAFETY, which has a ratio value of 0.7 for Italy when comparing two females versus two males. In all of the other cases, the values of the ratios are less than one, indicating a penalty for females. The highest ratio values are observed when comparing two females versus two males. For example, we can observe a high gap in terms of the dimension NUTRITION \& CLOTHING for Portugal (a ratio equal to 2.37; see Figure 3); this gap is confirmed by the significant p-value reported in Table 8 . For the dimension FINANCIAL ISSUES, we can observe rather high ratios for Portugal, Italy and Greece (values equal to 1.43, 1.25 and 1.43, respectively). All of these ratios indicate that males have higher wellbeing in terms of the corresponding capabilities.

To summarise, these final findings add further insights regarding the gender issue from a perspective that, as a far we know, is very poorly documented in the children's wellbeing literature. 
Since children's gender is an uncontrolled characteristic, the fact that it is connected to children's wellbeing suggest conducting further investigations. For example, complementing the present results with data regarding children's subjective wellbeing could help to better understand the reasons behind such evidence, as previous studies have found a generally lower level of happiness for females compared to males (Kaye-Tzadok et al., 2017; Tarki, 2011).

\section{Some final remarks}

As de Neubourg et al. (2012) highlight, "well-being analyses are especially useful when studying the situation of children because children do not have equal access to the household's income, and are more dependent on social goods and services". Accordingly, the ambition of this paper was to study children's wellbeing through the CA, with a special focus on gender differences within the intersection of family structure in four Mediterranean countries, namely, Italy, Spain, Portugal and Greece. This ambition has been fulfilled through an analysis that provides the following interesting conclusions and suggests further analysis to be developed in the future.

The supposed latent structure was proved to be adequate for all of the four countries included in the analysis, with the findings allowing a better understanding of children's wellbeing that goes beyond the solely monetary dimension. In other words, the necessity of continuing efforts for monitoring children's wellbeing from a multidimensional perspective should be emphasized. Thus, the monitoring of children's wellbeing may not remain within the bounds of strictly policy-relevant domains that consider only the monetary dimension, but rather it may go beyond and cover a broader set of dimensions and certainly consider the gender perspective, as we did in this analysis. The results revealed that in all four countries, households with children are more deprived than their counterparts. The comparison between the four countries also highlighted interesting differences when children's capabilities deprivation (the ability to play, to be well nourished and clothed, to have an adequate financial budget at household level, to have a social life, to live in an adequate 
housing, to live in a good environment and to be bodily healthy) is considered. In all of the countries, wellbeing in terms of the dimensions PLAY, NUTRITION \& CLOTHING and BODILY HEALTH is higher than wellbeing in terms of the dimensions FINANCIAL ISSUES, AFFILIATION \& SOCIAL LIFE, SHELTER and SAFETY. This fact indicates a "duality" of life discrepancy between the internal and external sphere of the families in all of the four countries.

Nevertheless, the major contribution of our paper concerns the effect of gender on children's wellbeing. Indeed, children's wellbeing in households with single parents, who are threatened by an overall lower multidimensional wellbeing, was analysed in terms of their parents' gender, and further significant effects in terms of several dimensions across the investigated countries were discovered. First, the direction of the effect - whether indicating a lower wellbeing for children living in female- or male-headed households - may differ for the same dimension across countries. The direction of the effect may depend on the different cultural norms prevailing in each country for the dimension examined, an aspect that is worthy of further investigation. Nevertheless, what is relevant in our study is that our findings add an inequality issue to the already-documented literature regarding the vulnerability of households with children.

The other gender aspect that was investigated in our study was children's gender. Our findings suggest that children's gender is particularly relevant for discriminating children's capabilities in Portugal, Italy and partially in Greece, whereas in Spain, the effect of children's gender seems to be almost negligible. With only a few exceptions, our results suggest that females are often more deprived than males.

Thus, we can deduce that particular attention should be paid to the gender issue when implementing policies aimed at increasing children's wellbeing. This is true for single-parent households, for which the gender of the parent is related to the children's wellbeing. Moreover, the household structure in terms of children's gender can also matter for children's wellbeing. Therefore, reduction of inequalities due to children's gender composition in the household should also be considered of primary importance. It is well known that failing to address child poverty likely leads 
to large costs in the future, associated with lower educational achievement, welfare dependence and poorer health. What must be further investigated are the potential consequences of underestimating the issue of children's multidimensional wellbeing exacerbated by gender inequality. By recognizing the importance of these issues, this study provides new insights into children's wellbeing from a cross-country, multidimensional and gendered perspective.

As a final concluding remark, it is worth noting that our study regarding children's wellbeing is limited by the use of secondary data from an adult perspective. Children should be the providers of the information collected to measure their wellbeing. This shortcoming stimulates further research about the topic and indicates the necessity of implementing a European survey targeted directly to children.

\section{References}

Addabbo T., Di Tommaso M.L., Maccagnan A, (2014). Gender Differences in Italian Children's Capabilities, Feminist Economics, 20(2), pp. 90-121.

Addabbo, T. and Di Tommaso, M. L. (2009). "Children capabilities and family characteristics in Italy," In M. Biggeri, J. Ballet, and F. Comim, (Eds.) Children and the Capability Approach: Child Labour, Education and Participation, (pp. ) New Dehli, India, Sage.

Aguayo I. H., Herraiz E. D., Marques E.M., Machado I., Almeida S. (2016). Child at Risk of Poverty or Social Exclusion: Comparative View Between Spain and Portugal in the European Context. Social Indicators Research, 129(3), pp. 961-978.

Axford N., Jodrell D., Hobbs T. (2014). Objective or Subjective Well-being? In Ben-Arieh A., Casas F., Frønes I. and Korbin J.E. (Eds.) Handbook of Child Well-Being. Theories, Methods and Policies in Global Perspective. Springer Reference.

Bartholomew, D. J. and Knott, M. (1999). Latent Variable Models and Factor Analysis, London: Arnold. 
Bastos A. and Machado C., (2009). Child poverty: a multidimensional measurement, International Journal of Social Economics, 36(3), pp. 237-251.

Bastos A., Leão G, Passos F.J., (2004). Child income poverty and child deprivation: an essay on measurement, International Journal of Social Economics, 31(11) pp. 1050-1060.

Ben-Arieh A., Casas F., Frønes I., and Korbin J. E. (2014). Multifaceted Concept of Child WellBeing In Ben-Arieh A., Casas F., Frønes I. and Korbin J. E. (Eds.) Handbook of Child WellBeing. Theories, Methods and Policies in Global Perspective. Dordrecht, Netherlands: Springer

Ben-Arieh, A. (2010). Developing indicators for child well-being in a changing context In C. McAuley, \& W. Rose (Eds.), Child Well--Being: Understanding Children's Lives pp. 129142. London, UK: Jessica Kingsley Publishers.

Ben-Arieh, A., \& Goerge, R. (2001). Beyond the numbers: How do we monitor the state of our children" Children and Youth Services Review, 23(8), pp. 603-631.

Ben Arieh, A., \& Goerge, R. M. (2006). Measuring and monitoring children's well-being: The Policy process. In A. Ben-Arieh, \& R. M. Goerge (Eds.), Indicators of Children's WellBeing pp. 21-30. Dordrecht, The Netherlands: Springer.

Berti, F., D’Agostino, A., Lemmi A., Neri L. (2014). Poverty and deprivation of immigrants vs. natives in Italy. International Journal of Social Economics, 41(8), 630 - 649.

Betti, G., Cheli, B., Lemmi, A. and Verma, V. (2006). Multidimensional and Longitudinal Poverty: An Integrated Fuzzy Approach. In: Lemmi, A. and Betti, G. (ed.), Fuzzy Set Approach to Multidimensional Poverty Measurement pp. 111-137. New York: Springer.

Betti G., Verma V. (2008). Fuzzy measures of the incidence of relative poverty and deprivation: a multi-dimensional perspective. Statistical Methods and Applications, 12(2), pp. 225-250.

Betti G. Gagliardi F., Lemmi A. and Verma V. (2015). Comparative Measures of Multidimensional Deprivation in the European Union, Empirical Economics, 49(3), pp. 1071-1100. 
Biggeri M., Libanora R., Mariani S., Menchini L. (2007). Children Conceptualizing their Capabilities: Results of a Survey Conducted during the First Children's World Congress on Child Labour. Journal of Human development, 7(1), pp. 59-83.

Brown F. (2012): The play behaviours of Roma children in Transylvania. International Journal of Play, 1(1), pp. 64-74.

Busetta, A. and Milito, A. M. (2010). Socio-Demographic Vulnerability: The Condition of Italian Young People. Social Indicators Research, 97(1), pp. 375-396.

Chen, W. and Corak, M. (2005). Child poverty and changes in child poverty, UNICEF Innocenti Research Centre, Florence, MA.

Demuth, S. and Brown, S. L. (2004). Family structure, family processes and adolescent delinquency: The significance of parental absence versus parental gender. Journal of Research in Crime and Delinquency, 41(1), pp. 58-81.

Dahl, G.B. and Moretti, E. (2008). The Demand for Sons. Review of Economic Studies, 75(1), pp. 1085-1120.

De Neubourg C., Bradshaw J., Yekaterina Chzhen Y., Main G., Martorano B., Menchini L. (2012). Child Deprivation, Multidimensional Poverty and Monetary Poverty in Europe, Working Paper 2012-02, UNICEF Innocenti Research Centre, Florence

Dinno A., (2015). Nonparametric pairwise multiple comparisons in independent groups using Dunn's test. The Stata Journal, 15(1), pp. 292-300

Durkin, K. (2005). Children's understanding of gender roles in society In Martyn Barret \& Eithne Buchanan-Barrow (Eds.) Children's understanding of society, pp. 135-159. New York: Psychology Press.

Di Tommaso, M. L. (2007). Children capabilities: a structural equation model for India. The Journal Socio-Economics, 36(1), pp. 436-450.

Engster D., Stensota H. O. (2011). Do Family Policy Regimes Matter for Children's Well-Being? Social Politics, 10(1), pp. 82-124. 
Gonzales, M. J., Jurado, T., Naldini, M (1999). Introduction: Interpreting the transformation of gender inequalities in Southern Europe. South European Society and Politics, 4(2), pp. 4-34.

Gonzales, M.J., Jurado, T., Naldini, M. (2013). Gender inequalities in Southern Europe. Women, work and welfare in the 1990s. New York: Routledge.

Hoyle R. H. and Panter A. T. (1995). Writing about structural equation models. In R. H. Hoyle (Ed.), Structural equation modeling: Concepts, issues, and applications, pp. 158-176. Thousand Oaks, CA: Sage.

Iversen, V. (2003). Intra-household inequality: a challenge for the capability approach? Feminist economics 9(2-3), pp. 93-115.

Jenkins, S. P. and Siedler, T. (2007). The intergenerational transmission of poverty in industrialized countries. ISER CPRC Working Paper 75. Chronic Poverty Research Centre

Jöreskog K. and A. Goldberger (1975). "Estimation of a Model with Multiple Indicators and Multiple Causes of a Single Latent Variable". Journal of the American Statistical Association, 70(351), pp. .

Kaplan, G. (2012). Economic crises: some thoughts on why, when and where they (might) matter for health - A tale of three countries. Social Science \& Medicine, 74(1), pp. 643-646.

Kaye-Tzadok A., Kim S. S., Main G. (2017). Children's subjective well-being in relation to genderWhat can we learn from dissatisfied children? Children and Youth Services Review, 80(1), pp. 96-104.

Klasen S. (2004). Gender-related Indicators of Well-being, Discussion Paper No. 2004/05, WIDER Word Institute for Development of Economics Research, United nation University.

Krishnakumar, J. (2007). "Going Beyond Functionings to Capabilities: An Econometric Model to Explain and Estimate Capabilities. Journal of Human Development and Capabilities, 8(1), pp. 39-63.

Krishnakumar, J. and Ballon, P. (2008). Estimating Basic Capabilities: A Structural Equation Model Applied to Bolivia. World Development, 36(4), pp. 992-1010. 
Kruskal, W.H. and Wallis, W.A. (1952). Use of ranks in one-criterion variance analysis. Journal of the American Statistical Association, 47(1), pp. 583-621.

Kornrich, S., \& Eger, M.A. (2016). Family life in context: men and women's perceptions of fairness and satisfaction across thirty countries. Social Politics, 23(1), pp. 40-69.

Lareau, A. (2003). Unequal childhoods: gender, race, and family life. Berkley: University of California Press.

Lemmi, A., Verma, V., Betti, G., Neri, L., Gagliardi, F., Tarditi, G., Ferretti, C., Kordos, J., Panek, T., Szukiełojć-Bieńkuńska, A., Szulc, A., Zięba, A. (2010). Multidimensional and fuzzy indicators developments, Deliverable of the FP7 project SAMPLE (Small Area Methods for Poverty and Living Conditions Estimates), EU-FP7-SSH-2007-1.

Lewis, J \& Giullari, S. (2005). The adult worker model family, gender equality and care: the search for new policy principles and the possibilities and problems of a capability approach. Economy \& Society, 34(1), pp. 76-104.

Lippman, L. H. (2007). Indicators and indices of child well-being: A brief American history. Social Indicators Research, 83(1), pp. 39-53.

Lippman, L. H., Moore, K. A., \& McIntosh, H. (2011). Positive Indicators of child well-being: a conceptual framework, measures, and methodological issues. Applied Research in Quality of Life, 6(4), pp. 425-449.

Marks, J., Bun, L.C. and McHale, S.M. (2009). Family Patterns of Gender Role Attitudes. Sex roles, 61(3-4), pp. 221-234.

McHale, S.M., Crouter, A.C., Whiteman, S.D. (2003). The family contexts of gender development in childhood and adolescence. Social Development, 12(1), pp. 125-148.

Modroño P.R., Gálvez-Muñoz L., Matus-López M. and Domínguez-Serrano M. (2013). A gender analysis of children's well-being and capabilities through time use data, DEMB Working Paper Series N. 9, Dipartimento Economia Marco Biagi 
Nilsson, E.-L. (2016). Analyzing Gender Differences in the Relationship between Family Influences and Adolescent Offending among Boys and Girls. Child Indicators Research.

Nunnally, J.C. and Bernstein, I.H. (1994). Psychometric theory (3rd Ed.). New York: McGraw-Hill. Nussbaum, M. (2006). Education and democratic citizenship: Capabilities and quality education. Journal of Human Development, 7(3), pp. 385-395

Potsi, A., D’Agostino, A., Giusti, C., Porciani, L. (2016). Childhood and capability deprivation in Italy: a multidimensional and fuzzy set approach. Quality \& Quantity, 50(6), pp. 2571-2590.

Potsi A., D'Agostino A., Giusti C. (2017). Children's well-being in times of crisis in PIIGS countries In H.-U. Otto, S. Pantazis, H. Ziegler, A. Potsi (Eds.) Human Development in Times of Crisis Renegotiating Social Justice, pp. 79-106. New York: Palgrave Macmillan.

Püss, T., Viies, M., Maldre, R. (2010). EU-12 Countries in The Context of European Social Model Types. International Business \& Economics Research Journal, 9(12), pp. 37-48.

Raghavan R. and Alexandrova A. (2015). Toward a Theory of Child Well-being, Social Indicators Research, 121(1), pp. 887-929.

Raley, S. and Bianchi, S. (2006). Sons, daughters, and family processes: Does Gender of Children Matter? Annual Review of Scociology, 32(1), pp. 401-421.

Richardson, D., Hoelscher, P. and Bradshaw, J. (2008). Child well-being in Central and Eastern European countries (CEE) and the Commonwealth of Independent States (CIS). Child Indicators Research, 1(3), pp. 211-250.

Roeters A. and Gracia P. (2016). Child Care Time, Parents' Well-Being, and Gender: Evidence from the American Time Use Survey. Journal of Child and Family Studies, 25(1), pp. 24692479.

Rollero C., Gattino S. and De Piccoli N. (2014). A Gender Lens on Quality of Life: The Role of Sense of Community, Perceived Social Support, Self-Reported Health and Income. Social Indicators Research, 116(1), pp. 887-898. DOI 10.1007/s11205-013-0316-9 
Schmitt, N. (1996). Uses and abuses of coefficient alpha. Psychological Assessment, 8(4), pp. 350353.

Sen A. K. (1985). Commodities and Capabilities. North-Holland, Amsterdam.

Sen, A. (1993). Capability and well-being. In M. Nussbaum, \& A. Sen (Eds.), The quality of life (pp. 30-53). Oxford, England: Clarendon Press.

Sen, A. (1999). Development as freedom (1st ed.). New York: Oxford University Press.

Sen, A. K. (2009). The idea of Justice. Penguin: New York.

TÁRKI (2010). Child Poverty and Child Well-Being in the European Union. Report prepared for the DG Employment, Social Affairs and Equal Opportunities of the European Commission, Budapest.

TÁRKI (2011). Child well-being in the European Union. Better monitoring instruments for better policies. Report prepared for the State Secretariat for social inclusion of the Ministry of Public Administration and Justice. Available on line at: www.tarki.hu/en/isẹpi

Volkert J. and Schneider F. (2012). A Literature Survey of Disaggregating General Well-being: Empirical Capability Approach Assessments of Young and Old Generations in Affluent Countries. Sociology Study, 2(6) pp. 397-416.

Walker, M. and Unterhalter, E. (2007). The Capability Approach: its potential for work in education In M. Walker and E. Unterhalter (Eds.), Amartya Sen's capability approach and social justice in education (pp. 1-18). London/New York: Palgrave.

Wall K. and Escobedo A. (2013). Parental Leave Policies, Gender Equity and Family Well-Being in Europe: A Comparative Perspective In A. Moreno Mínguez (Ed.), Family Well-being (pp. 103-129). European Perspectives. Netherlands: Springer.

Watson D., Maître B., Whelan C.T. (2012). Understanding Childhood Deprivation in Ireland, Social Inclusion Report No. 2, Department of Social Protection

West, C., and Zimmerman, C. (1987). Doing gender. Gender \& Society, 1(1), pp. 125-151. 